\title{
Nerve Growth Factor Prevents Both Neuroretinal Programmed Cell Death and Capillary Pathology in Experimental Diabetes
}

\author{
Hans-Peter Hammes, * Howard J. Federoff, ${ }^{\dagger}$ and \\ Michael Brownlee ${ }^{\ddagger}$ \\ *III. Medizinische Klinik und Poliklinik, Zentrum fur Innere Medizin, \\ Justus-Liebig-Universitat, Giessen, Germany \\ ${ }^{\dagger}$ Department of Neuroscience, Albert Einstein College of Medicine, \\ Bronx, New York, U.S.A. \\ ${ }^{\ddagger}$ Diabetes Research Center, Albert Einstein College of Medicine, \\ Bronx, New York, U.S.A.
}

\begin{abstract}
Background: Chronic diabetes causes structural changes in the retinal capillaries of nearly all patients with a disease duration of more than 15 years. Acellular occluded vessels cause hypoxia, which stimulates sightthreatening abnormal angiogenesis in $50 \%$ of all type I diabetic patients. The mechanism by which diabetes produces acellular retinal capillaries is unknown.

Materials and Methods: In this study, evidence of programmed cell death (PCD) was sought in the retinas of early diabetic rats, and the effect of nerve growth factor (NGF) on PCD and capillary morphology was evaluated.
\end{abstract}

Results: Diabetes induced PCD primarily in retinal gan- glion cells (RGC) and Muller cells. This was associated with a transdifferentiation of Muller cells into an injuryassociated glial fibrillary acidic protein (GFAP)-expressing phenotype, and an up-regulation of the low-affinity NGF receptor p75 ${ }^{\text {NGFR }}$ on both RGC and Muller cells. NGF treatment of diabetic rats prevented both early PCD in RGC and Muller cells, and the development of pericyte loss and acellular occluded capillaries.

Conclusions: These data provide new insight into the mechanism of diabetic retinal vascular damage, and suggest that NGF or other neurotrophic factors may have potential as therapeutic agents for the prevention of human diabetic retinopathy.

\section{INTRODUCTION}

Chronic diabetes ultimately produces structural changes in the retinal capillaries of nearly all patients with a disease duration of more than 15 years $(1,2)$. The most characteristic structural change in both humans and rodents is a loss of capillary pericytes with a concomitant thickening of the basement membrane resulting in acellular, occluded vessels (3). With time, the retinal hypoxia induced by these changes stimulates sightthreatening abnormal angiogenesis in perhaps

Address correspondence and reprint requests to: Michael Brownlee, Diabetes Research Center, F531, Albert Einstein College of Medicine, 1300 Morris Park Avenue, Bronx, NY 10461 .
$50 \%$ of all type I diabetic patients (4). Current therapy with laser photocoagulation reduces the risk of severe visual loss by only about $50 \%$ and carries with it side effects and risks (5).

The mechanism by which diabetes produces acellular retinal capillaries is unknown, but current hypotheses focus on direct damage to capillary cells by hyperglycemia through increased polyol pathway flux, increased de novo diacylglycerol synthesis, altered intracellular redox state, or formation of advanced glycation endproducts $(6-10)$. A common mechanistic event in the development of diabetic retinal acellular capillaries could be the induction of programmed cell death (PCD). PCD is a genetically encoded 
intrinsic cell suicide program whose activation is modulated by a multitude of factors that converge on common final steps to give a characteristic morphologic and biochemical phenotype $(11,12)$. In this study, we demonstrate that diabetes causes PCD in p $75^{\mathrm{NGFR}}$-expressing neuroretinal cells. Nerve growth factor (NGF) treatment prevents both diabetes-induced PCD in the neuroretina and diabetes-specific pathology in the vascular retina.

\section{MATERIALS AND METHODS}

\section{Experimental Diabetes}

Male Wistar rats weighing between 200 and 250 $\mathrm{g}$ were used in these experiments. In each of the experiments, rats were made diabetic by a single intravenous injection of streptozotocin at a dose of $65 \mathrm{mg} / \mathrm{kg}$. Serum glucose levels were measured 1 week later, and all animals with levels less than $300 \mathrm{mg} / \mathrm{dl}$ were excluded. After 15 weeks of diabetes, animals were humanely sacrificed, and the eyes were immediately removed. One eye was snap frozen in liquid nitrogen and the other was fixed in $4 \%$ formalin.

\section{PCD, GFAP, Vimentin, and ${\text { p } 75^{\text {NGFR }}}$ Measurements}

Vertical cryostat sections $(7 \mu \mathrm{m})$ were fixed in acetone for $5 \mathrm{~min}$ and stored at $-70^{\circ}$ until use. The extent and location of PCD was determined in using the ApopTag kit (Oncor, Gaithersburg, $\mathrm{MD}$, U.S.A.) for labeling new $3^{\prime}-\mathrm{OH}$ ends generated by PCD-induced DNA fragmentation according to the manufacturer's instructions. Glial fibrillary acidic protein (GFAP) and $775^{\text {NGFR }}$ expression was detected by incubating cryostat sections on polylysine-coated glass slides with either polyclonal GFAP antibody (1:250; DAKO, Hamburg, Germany), monoclonal vimentin antibody (clone V9, 1:200; Boehringer-Mannheim, Mannheim, Germany), or a monoclonal p75 ${ }^{\text {NGFR }}$ antibody (clone 192, 1:00; Oncogene Science, Hamburg, Germany), followed by TRITC- or FITClabeled secondary antibodies (1:20, DAKO).

\section{$I^{125}$-NGF Autoradiography}

$\mathrm{I}^{125}$-NGF autoradiography was performed according to the method of Altar et al. (13). In brief, $7-\mu \mathrm{m}$ cryostat sections were preincubated for $3 \mathrm{hr}$ in DMEM with 10\% FCS, $25 \mathrm{mM}$ Hepes,
$0.5 \mathrm{mM} \mathrm{MgCl} 2,4 \mu \mathrm{g} / \mathrm{ml}$ leupeptin, and $0.5 \mathrm{mM}$ PMSF. The sections were then incubated for 3.5 hr with I ${ }^{125}$-NGF $\left(4.2 \times 10^{-10} \mathrm{M}\right)$. Slides were washed, fixed in $2 \%$ paraformaldehyde in $0.2 \mathrm{M}$ phosphate buffer, and dipped in X-ray emulsion and exposed for 7 days. Quantitative measurements were performed using an Olympus CUE2 image analyzing system.

\section{Administration of NGF}

Treated diabetic animals $(n=12)$ received NGF ( $5 \mathrm{mg} / \mathrm{kg}$ three times per week) for 14 weeks. Untreated diabetic controls $(n=12)$ received vehicle alone according to the same schedule. Recombinant human NGF was generously provided by Genentech (South San Francisco, CA, U.S.A.).

\section{Retinal Digest Preparations}

Retinal vascular preparations were obtained from formalin-fixed eyes using a modification of the technique of Kuwabara and Cogan (14). Samples were digested with pepsin $(5 \%$ in $0.2 \%$ $\mathrm{HCl})$ for $1.5 \mathrm{hr}$ and trypsin $(2.5 \%$ in $0.2 \mathrm{M}$ Tris $)$ for $15-30 \mathrm{~min}$, and the isolated retinal vasculature was stained with PAS.

\section{Quantitative Retinal Morphometry}

The total number of pericytes was counted in 10 randomly selected fields of the retina using an Olympus CUE2 analyzing system. This number was normalized to the relative capillary density (pericytes $/ \mathrm{mm}^{2}$ of retinal area). Acellular capillaries were quantitated by a modification of the method of Engerman and Kern (15). A grid of 100 fields covering a total area of $6.76 \mathrm{~mm}^{2}$ of retinal area was used. Each field containing acellular capillary segments was recorded as positive, and values were normalized to $\mathrm{mm}^{2}$ of retinal area. Morphometry was performed blinded to the identity of the samples.

\section{RESULTS}

Evidence of PCD was sought in the retinae of early diabetic rats, using the ApopTag method for labeling new $3^{\prime}-\mathrm{OH}$ ends generated by PCD-induced DNA fragmentation (16). Vertical cryostat sections of nondiabetic retinae stained with this procedure were essentially negative (Fig. la). In contrast, PCD was present in cell bodies of both 

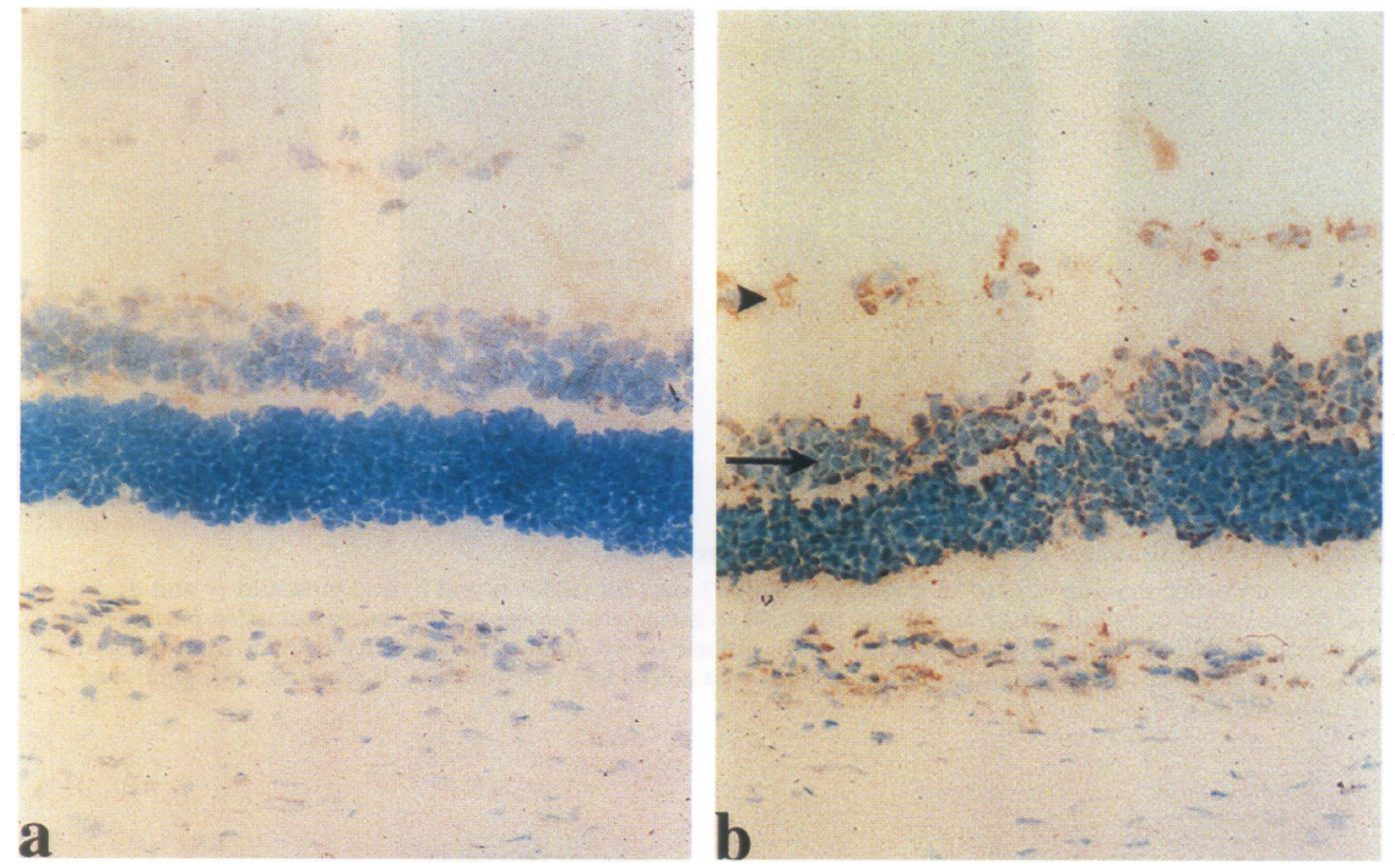

FIG. 1. Effect of diabetes on programmed cell death in the retina

Histochemical labeling of DNA fragmentation in vertical cryostat sections $(7 \mu \mathrm{m})$ using the Apoptag kit. Sections from nondiabetics (a) do not show PCD, while sections from diabetics (b) show PCD in the ganglion cell layer (arrowhead) and in Muller cell-containing inner nuclear layer (arrow). (Original magnification: 250×.)

ganglion cells and Muller cells in the inner nuclear layer of corresponding sections from diabetic rats (Fig. 1b). Diabetic capillary cells on flat-mount retinal digests did not exhibit significant PCD.

Since Muller cell injury has been associated with transdifferentiation into a GFAP-expressing phenotype that is normally confined to astrocytes (17-19), GFAP immunoreactivity was determined in nondiabetic and in diabetic retinas. In nondiabetics, GFAP was only present in astrocytes ensheathing capillaries from the ganglion cell layer to the inner nuclear layer (Fig. 2a). In diabetic retinas, GFAP immunoreactivity was strongly up-regulated and extended from the ganglion cell layer through the outer nuclear layer in a pattern consistent with the distribution of Muller cells (Fig. 2b). This was confirmed by immunostaining with a Muller cell-specific marker, vimentin, which colocalized with GFAP (Fig. $2 \mathrm{c}$ and d).

Muller and retinal ganglion cells (RGC) are the only cells in the neuroretina that express the low-affinity NGF receptor p $75^{\text {NGFR }}(20)$. In some neuronal cells, expression of this receptor induces PCD constitutively when p75 ${ }^{\text {NGFR }}$ is unbound. PCD is inhibited when p75 ${ }^{\text {NGFR }}$ is bound by NGF (21). Therefore, $p 75^{\mathrm{NGFR}}$ expression was evaluated in normal and diabetic retinas using monoclonal antibody 192-IgG for immunohistochemistry. In nondiabetics, p75 ${ }^{\mathrm{NGFR}}$ expression was weak and was localized from the ganglion cell layer to the inner nuclear layer of the retina (Fig. 3a). Diabetes caused a strong up-regulation of p $75^{\text {NGFR }}$ immunoreactivity extending from the ganglion cell layer to the outer nuclear layer (Fig. 3b). In diabetic retinas, p75 ${ }^{\mathrm{NGFR}}$ colocalized with GFAP immunoreactivity (data not shown), suggesting that Muller cells were the major cell type with $\mathrm{p} 75^{\mathrm{NGFR}}$ up-regulation. This up-regulation was accompanied by an increase in available NGF binding sites, as determined by exogenous ${ }^{125}$ I-NGF binding (13) (Fig. 4). Quantitation of binding to the innermost layers of the retina by image analysis showed a 2 -fold increase in binding from the inner limiting membrane to the 

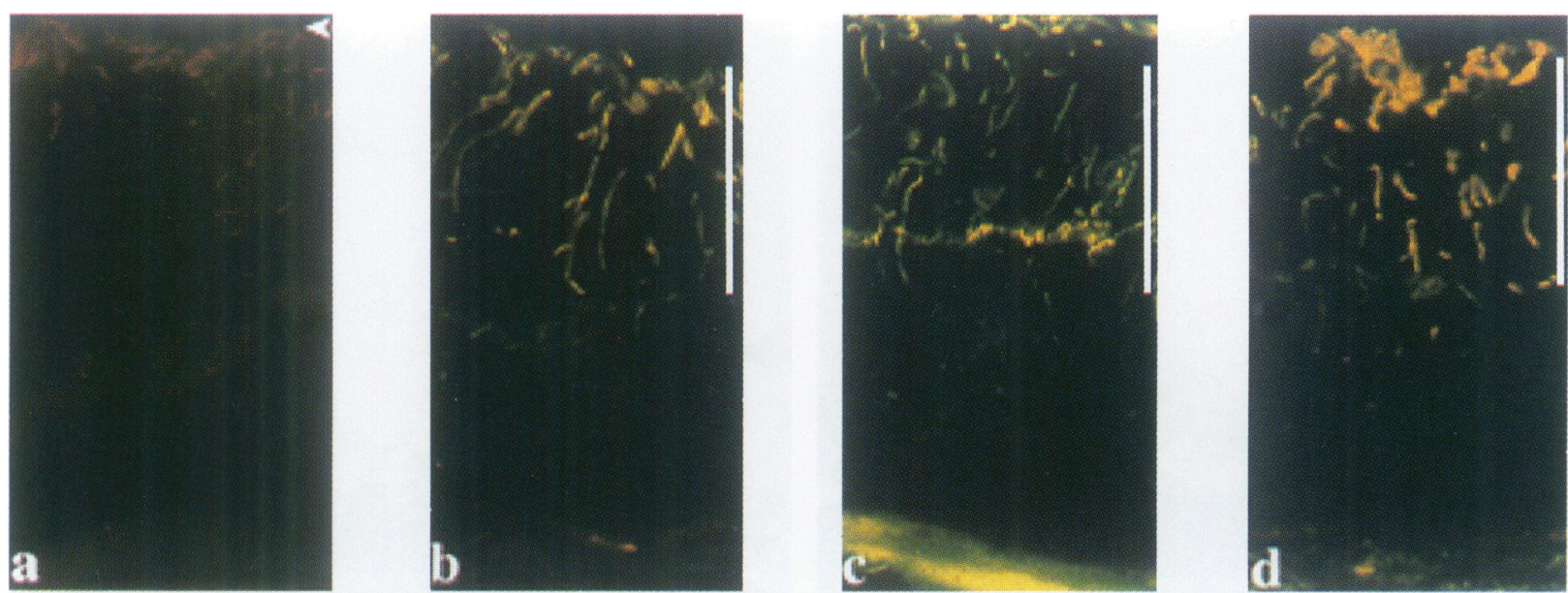

FIG. 2. Effect of diabetes on GFAP expression in the retina

Immunofluorescent staining of vertical cryostat sections $(7 \mu \mathrm{m})$ for GFAP $(\mathrm{a}$ and $\mathrm{b})$ and vimentin (c and d). In nondiabetic retina ( $a$ and $c$ ), GFAP labeling is confined to astrocytes accompanying the vascularized part of the inner retina (white bar). In diabetic retina (b and d), intense GFAP immunofluorescence extends from the ganglion cell layer to the outer nuclear layer in a pattern that colocalizes to expression of vimentin. (Original magnification: $400 \times$.)

inner nuclear layer of diabetics compared with nondiabetics $(1.133 \pm 0.203$ versus $0.483 \pm$ 0.06; $p<0.001)$.

NGF treatment of diabetic rats prevented PCD in both RGC and Muller cells of diabetic retina (Fig. 5). Similarly, NGF treatment of diabetic rats prevented the development of both pericyte loss and acellular occluded capillaries as assessed by retinal digest preparations (10). Nondiabetic animals revealed a uniform distribution of endothelial cells and pericytes, a regular capillary wall width, and only a few acellular occluded vessels. Diabetes 15 weeks in duration led to striking increases in pericyte cell loss and capillary occlusion (Fig. 6). Quantitatively, diabetes induced a $34 \%$ loss of pericytes $(1850 \pm 200$ versus $2840 \pm 50$ cells $/ \mathrm{mm}^{2}$ of capillary area in diabetics and nondiabetics, respectively; $p<$ 0.001 ) and a nearly 8 -fold increase in acellular occluded vessels compared with nondiabetics (155 \pm 20 versus $20 \pm 2$ acellular capillaries/ $\mathrm{mm}^{2}$ of retinal area in diabetics and nondiabetics, respectively; $p=0.001$ ). In contrast, retinal vessels from NGF-treated diabetics were more similar to those of nondiabetics. The degree of pericyte loss was reduced by $76 \%(2600 \pm 200$; $p=0.001$ versus untreated diabetics) and the number of acellular capillaries was reduced by $75 \%(40 \pm 10 ; p<0.001)$ compared with untreated diabetics.

\section{DISCUSSION}

The prevention by NGF of diabetes-induced neuroretinal programmed cell death and capillary pathology is noteworthy in several respects. First, it establishes an important link between the neuroretina and the vascular retina that has heretofore been unrecognized. Although Muller cell processes are often found in close proximity to retinal capillaries, it has not been appreciated that injury or trophic stimulation of the neuroretina could influence the retinal vessels. Earlier light and electron microscopy studies in humans and rodents showed that diabetes induces degeneration and loss of RGC and Muller cells $(22,23)$. It was unclear, however, whether this degeneration occurred in parallel with but independent of diabetic vascular changes, or whether its occurrence caused, or resulted from, the vascular changes.

Second, these data provide some insight into the mechanism of diabetic neuroretinal and retinal vascular damage. They suggest that an early step in the pathogenesis of diabetic retinopathy is diabetes-induced damage and PCD in neuroretinal cells. NGF prevents PCD in these cells, just as it enhances the survival of axotomized RGC in the rat retina (24) and promotes the recovery of RGC after ischemic injury (25). The mechanisms by which diabetes activates PCD and NGF suppresses it in these cells remains to be elucidated. 

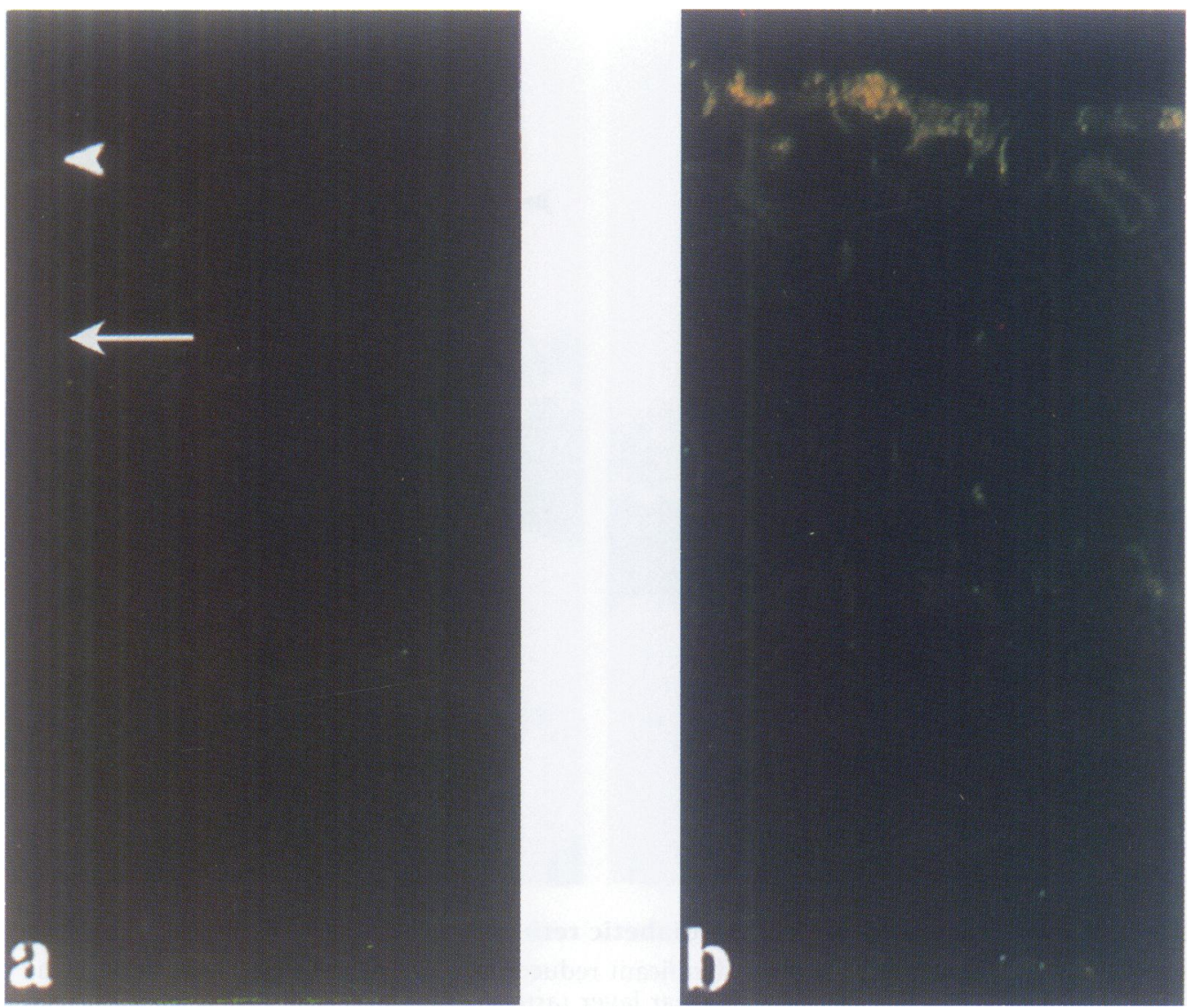

FIG. 3. Effect of diabetes on $p 75^{\mathrm{NGFR}}$ expression in the retina

In nondiabetics (a), immunofluorescence is weak and localized to the ganglion cell layer (white arrowhead) and processes extending through the inner nuclear layer (white arrow). In diabetics, immunofluorescence is more intense, and extends in a Muller cell-like distribution from the ganglion cell layer to the outer nuclear layer. (Original magnification: $400 \times$.)

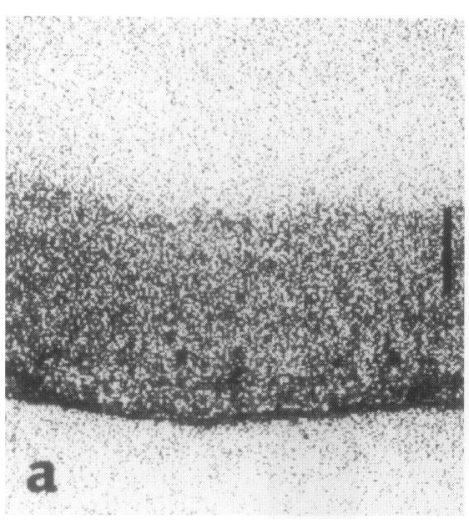

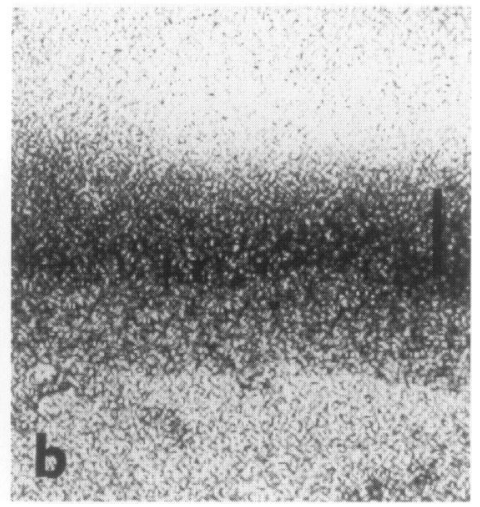

FIG. 4. Effect of diabetes on I $^{125}$-NGF binding

Specific binding of $\mathrm{I}^{125}$-NGF to nondiabetic (a) and diabetic (b) retina. (Original magnification: $250 \times$.)
The Muller cell-containing inner nuclear layer of the retina has been shown to contain vascular endothelial cell growth factor (26), a secreted polypeptide thought to play a role in the maintenance of vascular endothelium $(27,28)$. Loss of this trophic support may initiate the development of acellular capillaries.

Lastly, these results demonstrate that treatment with NGF prevents the development of diabetic retinopathy in an experimental animal 

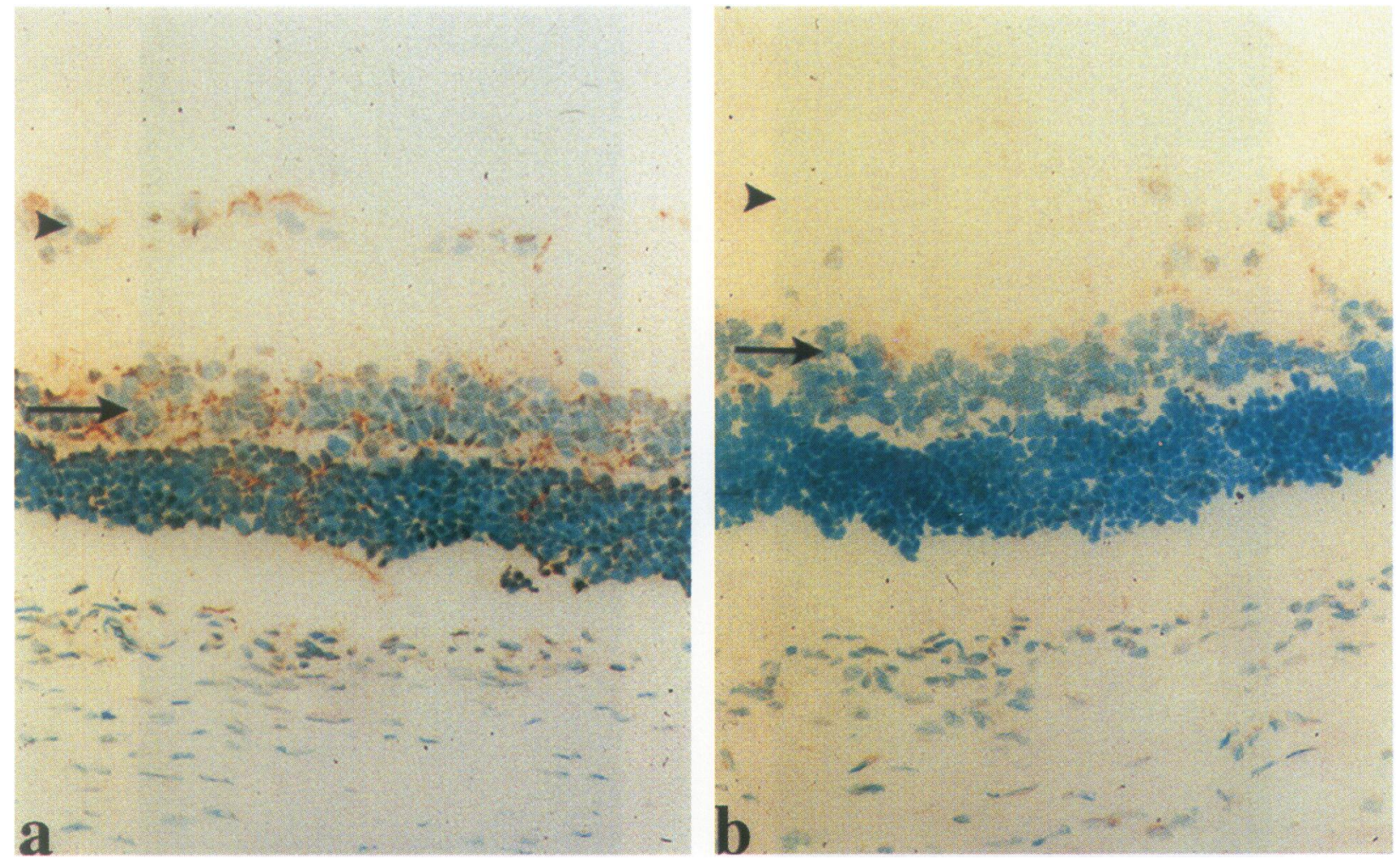

FIG. 5. Effect of NGF treatment on PCD in diabetic retina

Retina from NGF-treated diabetics (b) show a significant reduction in ApopTag labeled cells in both the ganglion cell layer (arrowhead) and in the inner nuclear layer (arrow) compared with retina from untreated diabetic controls (a). (Original magnification: $250 \times$.)

FIG. 6. Effect of diabetes and NGF treatment on pericyte loss and acellular capillary formation

The number of pericytes and acellular capillaries in nondiabetes (NC), untreated diabetics (DC), and NGFtreated diabetics (D)-NGF) was determined as described in Materials and Methods. For pericytes, $p<0.001 \mathrm{NC}$ versus DC and DC versus D-NGF. $p<$ $0.05 \mathrm{NC}$ versus D-N(iF. For acellular capillaries $p<0.001 \mathrm{NC}$ versus DC and DC versus D-NGF. $p<0.01 \mathrm{NC}$ versus D-NGF.

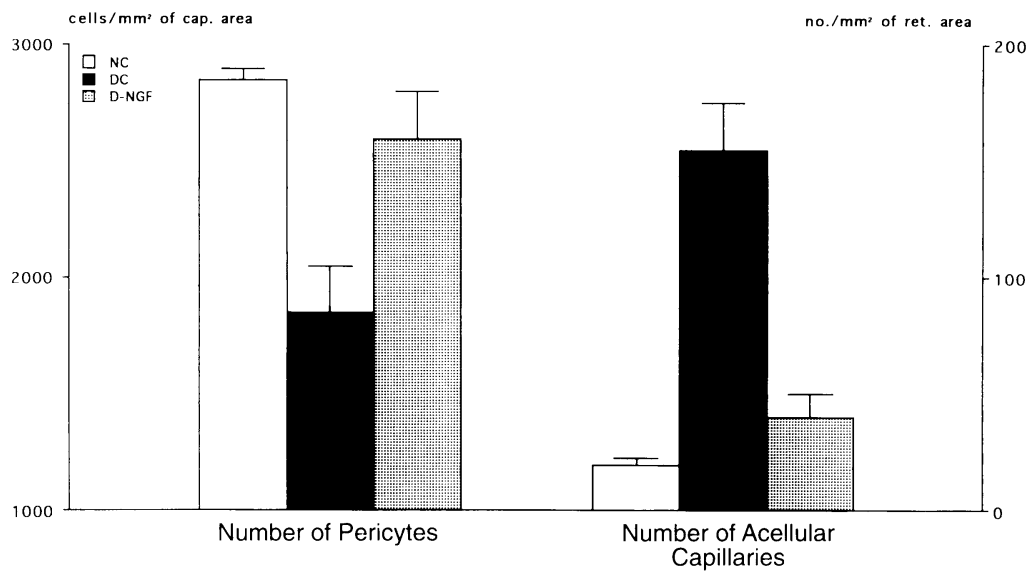


model. Thus, NGF or other neurotrophic factors may have future potential as therapeutic agents for the prevention of human diabetic retinopathy.

\section{ACKNOWLEDGMENTS}

This work was supported by National Institutes of Health Grant DK 33861-07, the Juvenile Diabetes Foundation, and Grant $\mathrm{Hal755/1-1}$ from the Deutsche Forschungsgemeinschaft. We would like to thank Dr. John A. Kessler, Albert Einstein College of Medicine, for making NGF-treated animal tissue available to us.

\section{REFERENCES}

1. Klein R, Klein BEK, Moss S, Davis MD, DeMets DL. (1984) The Wisconsin Epidemiologic Study of Diabetic Retinopathy II. Prevalence and risk of diabetic retinopathy when age at diagnosis is less than 30 years. Arch. Ophthalmol. 104: 520-526.

2. Klein R, Klein BEK, Moss S, Davis MD, DeMets DL. (1984) The Wisconsin Epidemiologic Study of Diabetic Retinopathy III. Prevalence and risk of diabetic retinopathy when age at diagnosis is 30 or more years. Arch. Ophthalmol. 102: 527-532.

3. Engerman RL. (1989) The pathogenesis of diabetic retinopathy. Diabetes 38: 1203-1 206.

4. Krolewski AS, Warram JH, Rand LI, Kahn CR. (1987) Epidemiologic approach to the etiology of Type I diabetes mellitus and its complications. N. Engl. J. Med. 317: 13901398.

5. The Diabetic Retinopathy Study Research Group. (1981) Photocoagulation treatment of proliferative diabetic retinopathy. Clinical application of DRS findings. Report No. 8 . Ophthalmology 88: 583-600.

6. Kinoshita JH. (1990) A thirty year journey in the polyol pathway. Exp. Eye Res. 50: 567573.

7. DeRubertis FR, Craven PA. (1994) Activation of protein kinase $C$ in glomerular cells in diabetes. Mechanisms and potential links to the pathogenesis of diabetic glomerulopathy. Diabetes 43: 1-8.

8. King GL, Shiba T, Oliver J, et al. (1994) Cellular and molecular abnormalities in the vascular endothelium of diabetes mellitus. Annu. Rev. Med. 45: 179-188.
9. Williamson JR, Chang $K$, Frangos $M$, et al. (1993) Hyperglycemic pseudohypoxia and diabetic complications. Diabetes 42: 801-813.

10. Hammes H-P, Martin S, Federlin K, et al. (1991) Aminoguanidine treatment inhibits the development of experimental diabetic retinopathy. Proc. Natl. Acad. Sci. U.S.A. 88: 11555-11558.

11. Wyllie AH. (1993) Apoptosis. Br. J. Cancer 67: 205-208.

12. Williams GT, Smith CA. (1993) Molecular regulation of apoptosis: Genetic controls on cell death. Cell 74: 777-779.

13. Altar CA, Burton LE, Bennet GL, DugichDjordjevic M. (1991) Recombinant human nerve growth factor is biologically active and labels novel high-affinity binding sites in rat brain. Proc. Natl. Acad. Sci. U.S.A. 88: 281285.

14. Kuwabara T, Cogan DG. (1960) Studies of retinal vascular patterns: normal architecture. Arch. Ophthalmol. 64: 904-911.

15. Engerman RL, Kern TS. (1987) Progression of diabetic retinopathy during good glycemic control. Diabetes 36: 808-812.

16. Gavrieli Y, Sherman Y, Ben-Sasson SA. (1992) Identification of programmed cell death in situ via specific labeling of nuclear DNA fragmentation. J. Cell Biol. 119: 493501 .

17. Okada M, Matsumura M, Ogino N, Honda Y. (1990) Muller cells in detached human retina express glial fibrillary acidic protein and vimentin. Graefes. Arch. Clin. Exp. Ophthal. 228: 467-474.

18. Osborne NN, Block F, Sontag KH. (1991) Reduction of ocular blood flow results in glial fibrillary acidic protein expression in rat retinal Muller cells. Vis. Neurosci. 7: 637-639.

19. Humphrey MF, Constable IJ, Chu Y, Wiffen S. (1993) A quantitative study of the lateral spread of Muller cell responses to retinal lesions in the rabbit. J. Comp. Neurol. 334: 545558.

20. Carmignoto G, Comelli MC, Candeo $\mathrm{P}$, et al. (1991) Expression of NGF receptor and NGF receptor mRNA in the developing and adult rat retina. Exp. Neurol. 111: 302-311.

21. Rabizadeh S, Oh J, Zhong LT, et al. (1993) Induction of apoptosis by the low-affinity NGF receptor. Science 261: 345-348.

22. Wolter JR. (1961) Diabetic retinopathy. Am. J. Ophthal. 51: 1123-1141.

23. Hori S, Mukai N. (1989) Ultrastructural lesions of retinal pericapillary Muller cells in 
streptozotocin-induced diabetic rats. Albrecht Von Graefes Archiv Klinische Exp. Opthalmol. 213: 1-9.

24. Carmignoto $G$, Maffei $L$, Candeo $P$, et al. (1989) Effect of NGF on the survival of rat retinal ganglion cells following optic nerve section. J. Neurosci. 9: 1263-1272.

25. Siliprandi R, Canella R, Carmignoto G. (1993) Nerve growth factor promotes functional recovery of retinal ganglion cells after ischemia. Invest. Opthalmol. Vis. Sci. 34: 32323245.

26. Pierce EA, Avery RL, Foley ED, Aiello LP,
Smith LE. (1995) Vascular endothelial growth factor/vascular permeability factor expression in a mouse model of retinal neovascularization. Proc. Natl. Acad. Sci. U.S.A. 92: 905-909.

27. Ferrara N. (1993) Vascular endothelial growth factor. Trends Cardiovasc. Med. 3: 244250.

28. Jakeman LB, Winer J, Bennet GL, Altar CA, Ferrara N. (1992) Binding sites for vascular endothelial growth factor are localized on endothelial cells in adult rat tissues. J. Clin. Invest. 89: 244-253.

Contributed by A. Cerami on May 15, 1995. 